\title{
A novel gelatin-based copolymer derived from chromium shavings waste as eco-friendly wood adhesive
}

\author{
Mao Yang ${ }^{1}$, Yanchun $\mathrm{Li}^{1}$, and Xugang Dang ${ }^{2}$ \\ ${ }^{1}$ Qilu University of Technology \\ ${ }^{2}$ Shaanxi University of Science and Technology
}

September 11, 2020

\begin{abstract}
One environmental friendly wood adhesive based on waterborne polyurethane (WPU) grafted gelatin (G) was investigated in this research. The $\mathrm{G}$ was extracted from chromium shavings waste firstly, and then mixed with pre-polymer emulsion of WPU to synthesis the graft copolymer (WPUG) via solvent-free emulsion copolymerization. The synthesized copolymer was characterized regarding the mechanical properties test, TGA, FT-IR and other analysis technology. The results indicated that the WPUG has good stability, water resisting. The film-forming and thermal stability of G were improved after reacted with the pre-polymer of WPU, and the temperature of maximum weight loss was over $350 \mathrm{oC}$. The WPUG adhesive has excellent bonding power and mechanical properties, the dry bonding strength could reach $4.21 \mathrm{MPa}$ when the $\mathrm{R}$ value was 1.5 . The preparation of copolymer not only can perfectly satisfy the need of environment-friendly wood adhesives, but can also effectively improve the recycling use of chromium shavings waste.
\end{abstract}

\section{Hosted file}

Manuscript.doc available at https://authorea.com/users/358408/articles/480582-a-novelgelatin-based-copolymer-derived-from-chromium-shavings-waste-as-eco-friendly-woodadhesive 